\title{
Mean distance of closest approach of ions: Lithium salts in aqueous solutions
}

\author{
Ana C.F. Ribeiro ${ }^{\mathrm{a}, 1}$, Victor M.M. Lobo ${ }^{\mathrm{a}, 1}$, Hugh D. Burrows ${ }^{\mathrm{a}, 1}$, Artur J.M. Valente ${ }^{\mathrm{a}, 1}$, \\ Ana M. Amado ${ }^{\text {a,1, }}$, Abílio J.F.N. Sobral ${ }^{\mathrm{a}, 1}$, Ana S.N. Teles ${ }^{\mathrm{a}, 1}$, \\ Cecília I.A.V. Santos ${ }^{b}$, Miguel A. Esteso ${ }^{b, *}$ \\ ${ }^{a}$ Department of Chemistry, University of Coimbra, 3004-535 Coimbra, Portugal \\ ${ }^{\mathrm{b}}$ Departamento de Química Física, Facultad de Farmacia, Universidad de Alcalá 28871 Alcalá de Henares, Spain
}

Received 2 August 2007; received in revised form 21 December 2007; accepted 18 January 2008

Available online 31 January 2008

\begin{abstract}
Numerical values for the mean distance of closest approach of ions, " $a$ ", for lithium salts in aqueous solutions are presented and discussed. These values were obtained from both experimental activity and diffusion coefficients, and estimated by using different theoretical approaches. (C) 2008 Elsevier B.V. All rights reserved.
\end{abstract}

Keywords: Ion size; Mean distance; Solutions; Transport properties

\section{Introduction}

The importance of lithium salts has long been recognized, and stems from their unique properties that allow them to be used in a wide range of applications. They have been indicated as ideal electrolytes for many electrochemical systems (batteries, fuel cells, double-layer capacitors, actuators, and dyesensitised solar cells) and are becoming increasingly important in areas such as renewable electricity generation [1-4]. They are also relevant to other areas, such as pharmacology, where they are used primarily in the treatment of bipolar disorder, but also find applications in reinforcing the efficacy of other antidepressant medication (lithium carbonate or alternatives such as lithium citrate $\left(\mathrm{Li}_{3} \mathrm{C}_{6} \mathrm{H}_{5} \mathrm{O}_{7}\right)$, lithium sulfate $\left(\mathrm{Li}_{2} \mathrm{SO}_{4}\right)$ and lithium aspartate and orotate) [5-8]. Other examples of their application can be found in fine chemical and polymer synthesis $(\mathrm{LiCl})$ and also as air purifiers $(\mathrm{LiOH})[9-11]$.

\footnotetext{
* Corresponding author.

E-mail addresses: anacfrib@ci.uc.pt (A.C.F. Ribeiro),vlobo@ci.uc.pt (V.M.M. Lobo), burrows@ci.uc.pt (H.D. Burrows), avalente@ci.uc.pt (A.J.M. Valente), ama1@portugalmail.pt (A.M. Amado), asobral@ci.uc.pt (A.J.F.N. Sobral), asnteles@gmail.com (A.S.N. Teles), cecilia.alves@uah.es (C.I.A.V. Santos), miguel.esteso@uah.es (M.A. Esteso).

${ }^{1}$ Tel.: +351 239 854460; fax: +351239827703.
}

New demands in science and technology for many of these applications require precise data concerning the fundamental thermodynamic and transport properties of ionic solutions [12-17]. For the explanation of this data, and perhaps more important, to estimate them when no experimental information is available, it is necessary to know parameters such as the "mean distance of closest approach of ions, $a$ " (when this parameter is expressed in angstroms, it is represented by $a$ ). While there is a clear need for accurate values of such thermodynamic data on electrolyte solutions, frequently this data is not available from the literature and must be calculated by means of either empirical expressions or theoretical models in which the parameter " $a$ " is involved. This parameter, " $a$ ", depends on the nature and concentration of the electrolyte, and also on the nature and concentration of other species present in the solution which participate in the formation of an ionic atmosphere. While there is no direct method for the measurement of the parameter " $a$ ", it can be estimated by using finite-ion-size equations from measurements of the activity and diffusion coefficients in solutions.

Turq et al. [18,19] developed a theory which illustrates simultaneously the different transport (e.g., diffusion) and equilibrium properties from very dilute solutions to high concentrations $\left(1-2 \mathrm{~mol} \mathrm{dm}^{-3}\right)$ by managing only the diameter of the ions as an adjustable parameter. It is possible to draw 
several qualitative conclusions from the systematic comparison of the magnitude of the " $a$ " parameter, calculated from those equations with the results of studies of unrelated properties, such as ionic mobilities, and with the results obtained from theoretical approaches. A variety of different techniques ranging from diffraction methods (X-rays, neutrons or electrons) to computer simulations (molecular dynamics or Monte Carlo methods) have been applied to this goal $[20,21]$. The available results of the ionic radius, particularly in solutions, up to the end of 1986 have been collected by Marcus in a review paper [21]. However, despite the intense work, the data available on this area are still scarce.

The objective of this paper is to present values for this " $a$ " parameter for lithium salts, estimated from the concurrence of experimental data and theoretical approaches, which will be useful, in our case, for pharmaceutical studies, but will have more general applications for all researchers working with solutions of electrolytes containing this cation.

\section{Estimation of " $a$ " from experimental mean ionic activity coefficients and diffusion coefficients}

For well-known reasons, the distance of closest approach, " $a$ ", within the Debye-Hückel theory, has to be regarded as an adjustable parameter in the various semi-empirical equations for activity coefficients $[6,7,22,23]$. Lobo [22] has estimated this parameter for a large number of electrolytes in aqueous solutions using data from [15] and the equation:

$\ln y_{ \pm}=-\frac{A\left|z_{1} z_{2} \sqrt{I}\right|}{1+B a \sqrt{I}}+b I$

where $a$ and $b$ are considered to be adjustable constants, $z_{1}$ and $z_{2}$ are the algebraic valences of a cation and of an anion, respectively, $y_{ \pm}$is the molality-scale mean ionic activity coefficient, and $I$ is the molality-scale ionic strength. The groups $A$ and $B$ are defined as

$A \equiv\left(2 \pi N_{\mathrm{A}} \rho_{A}\right)^{1 / 2}\left(\frac{e_{0}^{2}}{4 \pi \varepsilon_{0} \varepsilon_{r, A} k T}\right)^{3 / 2}$

$B \equiv e_{0}\left(\frac{2 N_{\mathrm{A}} \rho_{A}}{\varepsilon_{0} \varepsilon_{r, A} k T}\right)^{1 / 2}$.

In these equations (given in SI units), $N_{\mathrm{A}}$ is the Avogadro constant, $k$ is the Boltzmann constant, $e_{0}$ is the proton charge, $\varepsilon_{0}$ the permittivity of vacuum, $\rho_{A}$ the solvent density, $\varepsilon_{r, A}$ the solvent dielectric constant and $T$ the absolute temperature. Using the SI values for $N_{\mathrm{A}}, k, e_{0}$, and $\varepsilon_{0}$, and $\varepsilon_{r, A}=78.38$, $\rho_{A}=997.05 \mathrm{~kg} / \mathrm{m}^{3}$ for $\mathrm{H}_{2} \mathrm{O}$ at $25{ }^{\circ} \mathrm{C}$ and $1 \mathrm{~atm}$, we obtain $A=1.1744(\mathrm{~kg} / \mathrm{mol})^{1 / 2}, B=3.285 \times 10^{9}(\mathrm{~kg} / \mathrm{mol})^{1 / 2} \mathrm{~m}^{-1}$.

A computer program has been written for a specific electrolyte, where the values of the activity coefficients and the respective concentration are introduced. Successive calculations have been made, where $a$ varied from $1 \times 10^{-10} \mathrm{~m}$ to
$20 \times 10^{-10} \mathrm{~m}(1$ to $20 \AA)$ with increments of $0.01 \times 10^{-10} \mathrm{~m}$. For a given set of $a$ values at each concentration, the program calculates the corresponding set of values for $b$. Thus, a curve of $b$ against $a$ can be obtained for each concentration. When this calculation was extended to all concentrations for which data were available, the program found the best pairs of $a-b$ values which adjust simultaneously all these concentrations for that specific electrolyte. Table 1 shows the values obtained.

The mutual diffusion coefficient, $D$, of an electrolyte in $\mathrm{m}^{2} \mathrm{~s}^{-1}$ is given by

$D=\bar{M}\left(\frac{\left|z_{1}\right|+\left|z_{2}\right|}{\left|z_{1} z_{2}\right|}\right) \frac{R T}{c}\left(1+c \frac{\partial \ln y_{ \pm}}{\partial c}\right)$

where $R$ is the gas constant in $\mathrm{J} \mathrm{mol}^{-1} \mathrm{~K}^{-1}$ and the rest of the symbols have their usual meaning. The last term in parenthesis is the activity factor, in which $c$ means for the concentration in mol $\mathrm{m}^{-3}$, and $\bar{M}$, in $\mathrm{mol}^{2} \mathrm{~s} \mathrm{~m}^{-3} \mathrm{~kg}^{-1}$, is given by

$\bar{M}=\frac{1}{N_{\AA}^{2} e_{0}^{2}}\left(\frac{\lambda_{1}^{0} \lambda_{2}^{0}}{v_{2}\left|z_{2}\right| \lambda_{1}^{0}+v_{1}\left|z_{1}\right| \lambda_{2}^{0}}\right) c+\Delta \bar{M}^{\prime}+\Delta \bar{M}^{\prime \prime}$

The first- and second-order electrophoretic terms in Eq. (5) are given by

$\Delta \bar{M}^{\prime}=-\frac{c}{N_{\mathrm{A}}} \frac{\left(\left|z_{2}\right| \lambda_{1}^{0}-\left|z_{1}\right| \lambda_{2}^{0}\right)^{2}}{\left(\left|z_{1}\right| v_{1} \lambda_{2}^{0}+\left|z_{2}\right| v_{2} \lambda_{1}^{0}\right)^{2}} \frac{v_{1} v_{2}}{v_{1}+v_{2}} \frac{\kappa}{6 \pi \eta_{0}(1+\kappa a)}$

and

$\Delta \bar{M}^{\prime \prime}=\frac{\left(v_{1}\left|z_{2}\right| \lambda_{1}^{0}+v_{2}\left|z_{1}\right| \lambda_{2}^{0}\right)^{2}}{\left(v_{1}\left|z_{1}\right| \lambda_{2}^{0}+v_{2}\left|z_{2}\right| \lambda_{1}^{0}\right)^{2}} \frac{1}{\left(v_{1}+v_{2}\right)^{2}} \frac{1}{N_{\mathrm{A}}^{2}} \frac{\kappa^{4} \varphi(\kappa a)}{48 \pi^{2} \eta_{0}}$

where $\eta_{0}$ is the water viscosity, in $\mathrm{N} \mathrm{s} \mathrm{m}^{-2}, v_{1}$ and $v_{2}$ are the stoichiometric coefficients, $\lambda_{1}^{0}$ and $\lambda_{2}^{0}$ are the limiting molar conductivities of the cation and anion, respectively, in $\mathrm{m}^{2} \mathrm{~mol}^{-1}$ $\Omega^{-1}, \kappa$ is the "reciprocal average radius of ionic atmosphere" in $\mathrm{m}^{-1}$ (see e.g., [2-13]), $a$ is the mean distance of closest approach of ions in $\mathrm{m}, \phi(\kappa a)=\left|\mathrm{e}^{2 \kappa a} E_{\mathrm{i}}^{(2 \kappa a) /(1+\kappa a)}\right|$ has been tabulated by Harned and Owen [13], and the other symbols represent wellknown quantities [13]. In this equation, phenomena such as complexation, ionic solvation and/or ion association [24-26], and hydrolysis $[27,28]$ are not taken into consideration. From the above equations using our own measurements of $D$, and other literature values, we have calculated the parameter $a$. These values for $a$ are estimated by fitting to experimental data for $c \leq 0.1 \mathrm{~mol} \mathrm{dm}^{-3}$ to give theoretical values for $D$ whose deviations with respect to the experimental ones selected are less than $1-2 \%$, and are shown in Table 1.

Three experimental methods were used to measure mutual differential diffusion coefficients: conductimetric measurements (uncertainty $\pm 0.2 \%$ ) [29-39], Gouy and Rayleigh interferometry (uncertainty $<0.1 \%$ ) [32], and Taylor dispersion (uncertainty $\pm 1-2 \%$ ) [32]. The experimental diffusion coefficients, $D$, in aqueous solutions of electrolytes, at $25^{\circ} \mathrm{C}$, were collected from references $[15,32-39]$. They were used 
Table 1

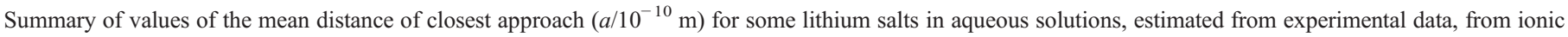
radius and from other theoretical approaches

\begin{tabular}{|c|c|c|c|c|c|c|c|c|}
\hline \multirow[t]{3}{*}{ Electrolyte } & \multirow{3}{*}{$\begin{array}{l}\frac{\text { Activity coefficients }}{\text { Eq. }(1)} \\
c \leq 1.0 \mathrm{M}\end{array}$} & \multirow{3}{*}{$\frac{\frac{\text { Diffusion coefficients }}{\text { Eq. (4) }}}{c \leq 0.1 \mathrm{M}}$} & \multirow[t]{3}{*}{ Kielland [9] } & \multirow{3}{*}{$\begin{array}{l}\text { Marcus [10] } \\
a=\mathrm{R}_{\text {cation }}+\mathrm{R}_{\text {anion }}\end{array}$} & \multirow{3}{*}{$\begin{array}{l}\text { Marcus }[10] \\
\overline{a=d_{\text {cation-water }}+d_{\text {anion-water }}}\end{array}$} & \multirow{3}{*}{$\begin{array}{l}\text { Ab initio } \\
d_{\text {ion-ion }}\end{array}$} & \multirow{2}{*}{\multicolumn{2}{|c|}{$\begin{array}{l}\text { Molecular } \\
\text { mechanics* }\end{array}$}} \\
\hline & & & & & & & & \\
\hline & & & & & & & a) & b) \\
\hline $\mathrm{LiF}$ & - & 2.0 & 4.8 & 2.0 & 4.8 & $1.6\left(d_{\mathrm{Li}-\mathrm{F}}\right)$ & 1.7 & 4.3 \\
\hline $\mathrm{LiBr}$ & 4.3 & - & 4.5 & 2.7 & 5.4 & $2.2\left(d_{\mathrm{Li}-\mathrm{Br}}\right)$ & 2.4 & 5.0 \\
\hline $\mathrm{LiCl}$ & 4.2 & $2.5 \leq a \leq 5.0$ & 4.5 & 2.5 & 5.3 & $2.1\left(d_{\mathrm{Li}-\mathrm{Cl}}\right)$ & 2.2 & 4.9 \\
\hline LiI & 4.2 & - & 4.5 & 3.0 & 5.7 & - & 2.6 & 5.2 \\
\hline $\mathrm{LiBrO}_{3}$ & - & - & 4.8 & - & - & $1.9\left(d_{\mathrm{Li}-\mathrm{O}}\right)$ & & \\
\hline $\mathrm{LiClO}$ & - & - & - & - & - & $1.6\left(d_{\mathrm{Li}-\mathrm{O}}\right)$ & & \\
\hline $\mathrm{LiClO}_{2}$ & - & - & 5.0 & - & - & $1.9\left(d_{\mathrm{Li}-\mathrm{O}}\right)$ & & \\
\hline $\mathrm{LiClO}_{3}$ & - & $2.5 \leq a \leq 5.0$ & 4.8 & - & - & - & & \\
\hline $\mathrm{LiClO}_{4}$ & 4.9 & - & 4.8 & - & - & - & & \\
\hline $\mathrm{LiCN}$ & - & - & 4.5 & - & - & - & $2.0(\mathrm{Li}-\mathrm{N})$ & 4.6 \\
\hline $\mathrm{LiC}_{2} \mathrm{O}_{4}$ & - & - & 5.2 & - & - & $1.8\left(d_{\mathrm{Li}-\mathrm{O}}\right)$ & & \\
\hline $\mathrm{Li}_{2} \mathrm{CO}_{3}$ & - & - & 5.2 & - & - & $1.8\left(d_{\mathrm{Li}-\mathrm{O}}\right)$ & & \\
\hline $\mathrm{Li}_{2} \mathrm{CrO}_{4}$ & - & - & 5.0 & - & - & - & & \\
\hline $\mathrm{LiH}_{2} \mathrm{AsO}_{4}$ & - & - & 5.0 & - & - & - & & \\
\hline $\mathrm{LiHCO}_{3}$ & - & - & 5.0 & - & - & $1.9\left(d_{\mathrm{Li}-\mathrm{O}}\right)$ & & \\
\hline $\mathrm{LiHC}_{2} \mathrm{O}_{4}$ & - & - & - & - & - & $1.9\left(d_{\mathrm{Li}-\mathrm{O}}\right)$ & & \\
\hline $\mathrm{Li}_{2} \mathrm{HPO}_{4}$ & - & - & 5.0 & - & - & - & & \\
\hline $\mathrm{LiH}_{2} \mathrm{PO}_{4}$ & - & - & 5.0 & 3.1 & 5.8 & - & & \\
\hline LiHS & - & - & 4.8 & - & - & $2.2\left(d_{\mathrm{Li}-\mathrm{S}}\right)$ & $2.8(\mathrm{Li}-\mathrm{S})$ & 5.2 \\
\hline $\mathrm{LiHSO}_{4}$ & - & - & - & - & - & $1.9\left(d_{\mathrm{Li}-\mathrm{O}}\right)$ & & \\
\hline $\mathrm{LiHSO}_{3}$ & - & - & 5.0 & - & - & $1.8\left(d_{\mathrm{Li}-\mathrm{O}}\right)$ & & \\
\hline $\mathrm{LiIO}_{3}$ & - & - & 5.0 & - & - & - & & \\
\hline $\mathrm{LiIO}_{4}$ & - & - & 4.8 & - & - & - & & \\
\hline $\mathrm{LiMnO}_{4}$ & - & - & 4.8 & - & - & - & & \\
\hline $\mathrm{Li}_{2} \mathrm{MoO}_{4}$ & - & - & 5.2 & 3.4 & 6.1 & - & & \\
\hline LiNCO & - & - & 4.8 & - & - & - & & \\
\hline $\mathrm{LiNO}_{2}$ & - & - & 4.5 & - & - & $1.9\left(d_{\mathrm{Li}-\mathrm{O}}\right)$ & & \\
\hline $\mathrm{LiNO}_{3}$ & - & $2.5 \leq a \leq 4.5$ & 4.5 & 2.5 & 5.2 & $1.9\left(d_{\mathrm{Li}-\mathrm{O}}\right)$ & & \\
\hline $\mathrm{LiOH}$ & - & 3.0 & 4.8 & - & - & $1.6\left(d_{\mathrm{Li}-\mathrm{O}}\right)$ & $1.6(\mathrm{Li}-\mathrm{O})$ & $4.2^{\mathrm{c}}$ \\
\hline $\mathrm{Li}_{3} \mathrm{PO}_{4}$ & - & - & 5.0 & - & - & - & & \\
\hline LiSCN & - & - & 4.8 & 3.1 & 5.9 & - & & \\
\hline $\mathrm{Li}_{2} \mathrm{~S}$ & - & - & 5.5 & - & - & $2.1\left(d_{\mathrm{Li}-\mathrm{S}}\right)$ & & \\
\hline $\mathrm{Li}_{2} \mathrm{SO}_{3}$ & - & - & 5.2 & - & - & $1.8\left(d_{\mathrm{Li}-\mathrm{O}}\right)$ & & \\
\hline $\mathrm{Li}_{2} \mathrm{SO}_{4}$ & - & 4.0 & 5.0 & 3.1 & 5.9 & $1.9\left(d_{\mathrm{Li}-\mathrm{O}}\right)$ & & \\
\hline $\mathrm{LiS}_{2} \mathrm{O}_{3}$ & - & - & 5.0 & - & - & - & & \\
\hline $\mathrm{Li}_{2} \mathrm{~S}_{2} \mathrm{O}_{4}$ & - & - & 5.5 & - & - & - & & \\
\hline $\mathrm{Li}_{2} \mathrm{~S}_{2} \mathrm{O}_{6}$ & - & - & 5.0 & - & - & - & & \\
\hline $\mathrm{Li}_{2} \mathrm{~S}_{2} \mathrm{O}_{8}$ & - & - & 5.0 & - & - & - & & \\
\hline $\mathrm{Li}_{2} \mathrm{SeO}_{4}$ & - & - & 5.0 & 3.3 & 6.0 & - & & \\
\hline $\mathrm{Li}_{2} \mathrm{WO}_{4}$ & - & - & 5.5 & 3.4 & 6.1 & - & & \\
\hline
\end{tabular}

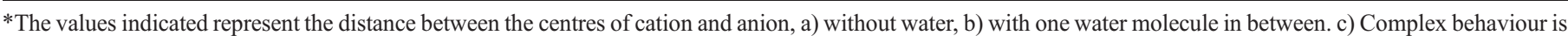

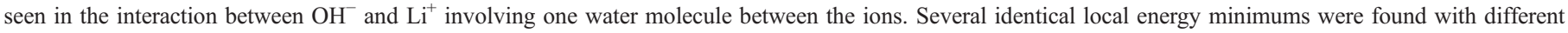
distances of closest approach, starting the calculations from different inputs. The value in the table is an average of three of these values.

to calculate the values of $a$ shown in Table 1, assuming the Onsager-Fuoss model Eq. (4) [16,37-39].

\section{Estimation of $a$, by different theoretical approaches}

\subsection{Estimations of a values from Kielland data}

From the ionic sizes reported by Kielland [20], values of $a$ were estimated as equal to the mean value of the effective radii of the hydrated ions that forms the electrolyte. These $a$ values are shown in the 4th column in Table 1. The diameters of inorganic ions, hydrated to different degrees, were calculated by using two different methods: from the crystal radius and deformability, using Bonino's equation for the cations [20], and from ionic mobilities [20].

\subsection{Estimation of a values from Marcus data}

Using the Marcus data [21] two approximations were performed to obtain the values of $a$ of several salts in aqueous solution. Firstly, the $a$ values were determined as the sum of the ionic radii $\left(R_{\text {ion }}\right)$ reported by Marcus [21]. The $R_{\text {ion }}$ values were obtained as the difference between the mean internuclear distance between a monoatomic ion (or the central atoms of a polyatomic ion), the oxygen atom of a water molecule in its first-hydration shell $\left(d_{\text {ion-water }}\right)$ and the half of the mean 
intermolecular distance between two water molecules in the bulk liquid water (the mean radius of a water molecule, $R_{\text {water }}=$ $(1.393 \pm 0.002) \times 10^{-10} \mathrm{~m}[21]$; this value was determined after considering the packaging effect produced by the electrostriction phenomenon derived from the strong electrical field near the ion [22]. That is, $R_{\text {ion }}=d_{\text {ion-water }}-R_{\text {water }}$ and $a=R_{\text {cation }}+R_{\text {anion }}$. These values are summarized in the fifth column in Table 1. For the determination of interparticle distances, $d_{\text {ion-water, }}$, different techniques have been used, such as diffraction methods (X-ray diffraction, neutron diffraction, X-ray absorption fine structure-EXAFS-measurements, etc.) and computer simulations (molecular dynamics and the Monte Carlo methods).

To account for the effect of the ion hydration shell on the $a$ values, a second approximation, considering the sum of the $d_{\text {ion-water }}$ values reported by Marcus [21], was also used. In this approach the $a$ values are determined as $a=d_{\text {cation-water }}{ }^{+}$ $d_{\text {anion-water }}$ The values found are collected in the sixth column in Table 1.

\subsection{Ab initio calculations}

The $a b$ initio calculations have been carried out using the Gaussian 98w (G98w) program package [40] adapted to a personal computer. Full geometry optimisations were performed, without any structural or symmetry constraint. All calculations were performed within the Density Functional Theory (DFT) approach, using the B3LYP method [41], which includes a mixture of Hartree-Fock (HF) and DFT exchange terms. The gradient-corrected correlation functional was used [42] (parameterised after Becke [43]), along with the doublezeta split valence basis set 6-31 $\mathrm{G}^{*}$ [44].

Two different theoretical models could be considered for simulating the cation-anion distance in dilute aqueous solution. In a simplest one, the cation-anion distance will be optimised without considering the presence of the solvent molecules, while in a second approximation, the first-hydration shell of the cation is considered. In the present paper, the first model was used. The calculated distances obtained are shown in column 7 of Table 1 and discussed on the basis of the corresponding experimentally predicted cation-anion distances.

\subsection{Molecular mechanics studies (MM2)}

Molecular mechanics studies are a valuable tool to interpret atom or ion dynamic relationships. They are simpler than $a b$ initio calculations, and are consequently faster, while still being sufficiently reliable to evaluate dynamic processes such as solvation changes around cations and anions, providing reasonable mean distances of approach between species in solution, involving dozens of molecules with hundreds of electrons.

Among the various MM methods, MM2 developed by Burkert and Allinger [45] is frequently taken as the reference in the area. Consequently, we have used it to investigate both the dynamic process of water solvation and the distribution of water molecules around the electrolytes discussed in this paper. The results obtained are summarized in the last column in Table 1.
These were obtained by considering three possibilities: a) no water molecules in between anion and cation (MM2-0), b) both ions separated by one water molecule (MM2-1) and c) two water molecules placed in between both ions (MM2-2).

\section{Results and discussion}

Table 1 summarizes the $a$ values found for 40 lithium salts in aqueous solution. For some of them, various values for this parameter are presented which have been estimated by using different experimental techniques and/or theoretical approaches here considered. This table shows some similarities to the results obtained for sodium salts [46]. That is, the $a b$ initio values and the values calculated from MM2-0 and Marcus data $\left(a=R_{1}+R_{2}\right)$ are similar, whereas those found from MM2-1 and the other Marcus data $\left(a=d_{\text {cation-water }}+d_{\text {anion-water }}\right)$, i.e., by considering one water molecule placed in between both ions, are larger. This is not unforeseen if we have in mind those estimations that correspond to the two very distant situations: the "bare" ions in contact each other and the ions arranged with one water molecule in the middle, respectively. Due to the complex nature of the structure of the electrolyte solution, it may be expected that this intermediate situation is more realistic.

By looking at Table 1, some other analogies with the sodium results [46] are observed. Thus, it can be seen that, in general, the values of $a$ obtained by fitting experimental activity coefficients data are greater than the sum of ionic radii in solution (or crystal-lattice spacing) or the interatomic distances, $d_{\text {ion-ion, }}$, what could be explained in terms of the presence of the hydration shell for both cations and anions. On the other hand, they are close to those obtained from Kielland's data, and are smaller than the sum of the mean ion-water internuclear distances. As equal as in the analysis of the sodium ion data, this fact can be interpreted on the basis of the presence of strong interactions between hydrated cations and anions, which would lead to some extent to the compaction of their hydration shells. At this point, it is necessary to bear in mind that these values have been obtained by using the D-H model (Eq. (1)) for which the ion-ion and ion-solvent interactions (which would be responsible of this compaction) are not taken into account, the fitting being essentially done through the mathematic adjustable parameters $a$ and $b$ (since in Eq. (1) the higher-order interaction terms are not considered but only the first-order one).

Relating to the $a$ values found from the fitting of experimental diffusion coefficients (by using Eq. (4)), it can be observed that these results are always lower than the Kielland's values and close to those obtained from the sum of ionic radii and calculated by ab initio and molecular mechanics techniques with no water molecules between the ions. One possible explanation can be attained by considering that the Onsager-Fuoss theory (Eq. (4)) disregards facts as the complex ions' presence as well as the ion-pairs formation, which could be responsible of the lowest values found for this $a$ parameter (that is, values comparable to the situation of baring ions in solution). However, as it can also be observed by looking at the values shown in Table 1, Eq. (4) is a little sensible to the 
change in the parameter $a$ value, which can be largely modified (up to reach values comparable to the Kielland ones) without affecting the fitting.

\section{Conclusions}

It is not possible to accurately know the mean distance of closest approach of ions, $a$, in an electrolyte solution, however desirable that would be. However, we present here several estimations of $a$ using different methods, which we believe will provide the researcher who needs to use this parameter an idea of the possible range of values. All of these are reasonable compromises to provide an appropriate value for this $a$ parameter for the particular problem under study. By taking the appropriate precautions, the most appropriate value may be chosen for a particular case, or values selected using one specific method of estimation. In the more general case, an appropriate average value may be the most suitable. We believe that the indications given in Sections 3 and 4 provide a basis for such a choice.

\section{Acknowledgements}

Financial support from FCT, FEDER, POCTI (QUI/39593/ 2001), POCI/AMB/55281/2004 is gratefully acknowledged.

\section{References}

[1] R. Kawano, H. Tokuda, T. Katakabe, et al., Kobunshi Ronbunshu 63 (2006) 31-40.

[2] A. Fernicola, B. Scrosati, H. Ohno, Ionics 12 (2006) 95-102.

[3] S. Chedarampet, Karthikeyan, M. Thelakkat, Inorg. Chim. Acta, In Press.

[4] P. Butler, C. Wagner, R. Guidotti, I. Francis, J. Power Sources 136 (2004) 240-245.

[5] F. Benedetti, B. Barbini, M.C. Fulgosi, et al., J. Clin. Psychiatry 66 (2005) $1535-1540$.

[6] A. Serretti, P. Artioli, R. Quartesan, Pharmacogenetics and Genomics 15 (2005) 61-67.

[7] R.E. Frost, F.S. Messiha, Brain Res. Bull. 11 (1983) 219-231.

[8] B.J. Pleuvry, Anaesth. Intensive Care Med. 5 (2004) 354-357.

[9] Y.G. Andreev, P.G. Bruce, Electrochim. Acta 45 (2000) 1417-1423.

[10] G. Costa, E. Pedemonte, S. Russo, E. Savà, Polymer 20 (1979) 713-718.

[11] M.M. Iovleva1, Fibre Chem. 33 (2001) 172-176.

[12] R.A. Robinson, R.H. Stokes, Electrolyte Solutions, second ed. Butterworths, London, 1959.

[13] H.S. Harned, B.B. Owen, The Physical Chemistry of Electrolytic Solutions, third ed.Reinhold Pub. Corp., New York, 1964.

[14] A.L. Horvath, Handbook of Aqueous Electrolyte Solutions. Physical Properties. Estimation and Correlation Methods, John Wiley and Sons, New York, 1985.

[15] V.M.M. Lobo, Handbook of Electrolyte Solutions, Elsevier, Amsterdam, 1990.

[16] L. Onsager, R.M. Fuoss, J. Phys. Chem. 36 (1932) 2689-2778.

[17] J.O'M. Bockris, A.K.N. Reddy, Modern Electrochemistry, Vol. 1, Plenum Press, New York, 1970.

[18] J.-F. Dufrêche, O. Bernard, P. Turq, J. Chem. Phys. 116 (2002) 2085-2097.

[19] J.-F. Dufrêche, O. Bernard, P. Turq, J. Mol. Liq. 118 (2005) 189-194.

[20] J. Kielland, J. Am. Chem. Soc. 59 (1937) 1675-1678.

[21] Y. Marcus, Chem. Rev. 88 (1988) 1475-1498.
[22] V.M.M. Lobo, Corros. Prot. Mater. 4 (1985) 13-19; V.M.M. Lobo, Corros. Prot. Mater. 4 (1985) 43-45.

[23] R.W. Gurney, Ionic Processes in Solution, Dover Publications, Inc., New York, 1953.

[24] V.M.M. Lobo, A.C.F. Ribeiro, Port. Electrochim. Acta 12 (1994) 29-41.

[25] H. Ohtaki, T. Radnai, Chem. Rev. 93 (1993) 1157-1204.

[26] V.M.M. Lobo, A.C.F. Ribeiro, Port. Electrochim. Acta 13 (1995) 41-62.

[27] C.F. Baes, R.E. Mesmer, The Hydrolysis of Cations, John Wiley \& Sons, New York, 1976.

[28] J. Burgess, Metal Ions in Solution, John Wiley \& Sons, Chichester, Sussex, England, 1978.

[29] V.M.M. Lobo, Diffusion and Thermal Diffusion in Solutions of Electrolytes, Ph.D. Thesis, Cambridge, 1971.

[30] J.N. Agar, V.M.M. Lobo, J. Chem. Soc., Faraday Trans. I 71 (1975) 1659-1666.

[31] V.M.M. Lobo, A.C.F. Ribeiro, A.J.M. Valente, Corros. Prot. Mater. 14 (1995) 14-21.

[32] H.J.V. Tyrrell, K.R. Harris, Diffusion in Liquids: a Theoretical and Experimental Study, Butterworths, London, 1984.

[33] V.M.M. Lobo, A.C.F. Ribeiro, L.M.P. Veríssimo, J. Mol. Liq. 78 (1998) 139-149.

[34] A.C.F. Ribeiro, V.M.M. Lobo, J.J.S. Natividade, J. Mol. Liq. 94 (2001) 61-66.

[35] V.M.M. Lobo, A.C.F. Ribeiro, L.M.P. Veríssimo, Ber. Bunsenges. Phys. Chem. 98 (1994) 205-208.

[36] V.M.M. Lobo, A.C.F. Ribeiro, L.M.P. Veríssimo, J. Chem. Eng. Data 39 (1994) 726-728.

[37] V.M.M. Lobo, Pure Appl. Chem. 65 (1993) 2613-2640.

[38] V.M.M. Lobo, A.C.F. Ribeiro, S.G.C.S. Andrade, Ber. Bunsenges. Phys. Chem. 99 (1995) 713-720.

[39] V.M.M. Lobo, A.C.F. Ribeiro, S.G.C.S. Andrade, Port. Electrochim. Acta 14 (1996) 45-124.

[40] Gaussian 98, Revision A.9, M.J. Frisch, G.W. Trucks, H.B. Schlegel, G.E. Scuseria, M.A. Robb, J.R. Cheeseman, V.G. Zakrzewski, J.A. Montgomery, Jr., R.E. Stratmann, J.C. Burant, S. Dapprich, J.M. Millam, A.D. Daniels, K.N. Kudin, M.C. Strain, O. Farkas, J. Tomasi, V. Barone, M. Cossi, R. Cammi, B. Mennucci, C. Pomelli, C. Adamo, S. Clifford, J. Ochterski, G. A. Petersson, P. Y. Ayala, Q. Cui, K. Morokuma, D.K. Malick, A.D. Rabuck, K. Raghavachari, J.B. Foresman, J. Cioslowski, J.V. Ortiz, A.G. Baboul, B.B. Stefanov, G. Liu, A. Liashenko, P. Piskorz, I. Komaromi, R. Gomperts, R.L. Martin, D.J. Fox, T. Keith, M.A. Al-Laham, C.Y. Peng, A. Nanayakkara, M. Challacombe, P.M.W. Gill, B. Johnson, W. Chen, M.W. Wong, J.L. Andres, C. Gonzalez, M. Head-Gordon, E.S. Replogle, J.A. Pople, Gaussian, Inc., Pittsburgh PA, 1998.

[41] (a) T.V. Russo, R.L. Martin, P.J. Hay, J. Phys. Chem. 99 (1995) 17085-17087; (b) A. Ignaczak, J.A.N.F. Gomes, Chem. Phys. Lett. 257 (1996) 609-615;

(c) F.A. Cotton, X. Feng, J. Am. Chem. Soc. 119 (1997) 7514-7520;

(d) T. Wagener, G. Frenking, Inorg. Chem. 37 (1998) 1805-1811;

(f) A. Ignaczak, J.A.N.F. Gomes, J. Electroanal. Chem. 420 (1997) 209-218;

(g) F.A. Cotton, X. Feng, J. Am. Chem. Soc. 120 (1998) 3387-3397.

[42] (a) C. Lee, W. Yang, R.G. Parr, Phys. Rev. B37 (1988) 785-789;

(b) B. Miehlich, A. Savin, H. Stoll, H. Preuss, Chem. Phys. Lett. 157 (1989) 200-206.

[43] (a) A. Becke, Phys. Rev. A38 (1988) 3098-3100;

(b) A. Becke, J. Chem. Phys. 98 (1993) 5648-5652.

[44] P.C. Hariharan, J.A. Pople, Theor. Chim. Acta 28 (1973) 213-222.

[45] Molecular Mechanics, Ulrich Burkert, Norman L. Allinger, ACS Monograph 177, American Chemical Society, Washington, DC, 1982.

[46] A.C.F. Ribeiro, Miguel A. Esteso, Victor M.M. Lobo, Hugh D. Burrows, Ana M. Amado, António M. Amorim da Costa, Abilio J.F.N. Sobral, Eduarda F.G. Azevedo, Maria A.F. Ribeiro, J. Mol. Liq. 128 (2006) 134-139. 